\title{
The need to change the method for defining mild airway obstruction
}

Dear colleagues, members of GOLD committee,

This letter arises from discussions and correspondence between colleagues involved in respiratory research or the diagnosis and treatment of lung diseases, as well as from a review of the literature on chronic obstructive pulmonary disease (COPD). As discussed below, it is written in the hope that we can persuade members of the Global Initiative for Chronic Obstructive Lung Disease (GOLD) committee to vote to change the method by which mild airway obstruction is defined by the GOLD guidelines.

We very much welcome the continued efforts of the GOLD group to stimulate interest and awareness of the high prevalence of COPD, its morbidity, effects on quality of life and on mortality. There is no doubt that COPD is a major public health problem of which the public, health workers and health authorities were insufficiently aware. It is therefore an important achievement that the World Health Organization (WHO), the European Respiratory Society (ERS), the American Thoracic Society (ATS), the Asian Pacific Society of Respirology (APSR), the Asociación Latinoamericana de Tórax (ALAT), and the World Organization of Family Doctors (WONCA) and many distinguished individuals have joined forces to increase awareness about the burden of disease, by publishing reports and guidelines for diagnostic procedures and interventions which have been adopted by numerous international and national organisations.

However, there is one area which has given rise to continuous published criticism: the criterion for confirming airway obstruction. It is well known that the forced expiratory volume in $1 \mathrm{~s}(\mathrm{FEV} 1) /$ forced vital capacity (FVC) ratio declines with increasing age and height, even in healthy lifelong nonsmokers, in whom the lower limit of normal drops below a ratio of 0.7 from about 45 yrs of age [1-6]. It has been shown [4-27] that using the fixed ratio causes up to $50 \%$ over-diagnosis (misclassification) above that age. Adult smokers suspected of having COPD are not at increased risk of respiratory symptoms, respiratory morbidity, or all-cause mortality until the ratio falls below the age-corrected 5 th percentile lower limit of the normal range $[26,28]$.

The present GOLD guidelines on the spirometric assessment of airway obstruction are scientifically untenable [1, 29-31] and have given rise to editorials in Chest [32], the European Respiratory Journal [17], the American Journal of Respiratory and Critical Care Medicine [33], COPD: Journal of Chronic Obstructive Pulmonary Disease [34], and Respiratory Care [35], with a plea for revision. The very significant over-diagnosis in elderly subjects

This open letter has been previously published in the Primary Care Respiratory Journal (Prim Care Respir J 2010; 19: 288-291), Respiration (Respiration 2010; 80: 265-268), Respiratory Care (Respir Care 2010; 55: 1397-1398), Revues des Maladies Respiratoires (Rev Mal Respir 2010; 27 : 1003-1007) and on the website of the Association for Respiratory Technology and Physiology (www.artp.org.uk). due to this guideline is akin to selling sickness. There is considerable psychological impact, and there are wider health consequences of incorrectly being labelled as having COPD, a syndrome associated with a poor prognosis with regard to morbidity, quality of life and mortality and therefore a psychological burden for the subject, his family and wider environment. Subjects erroneously labelled become a target for individual and lifelong interventions which are associated with side-effects. This is all the more unacceptable since evidence for the long-term effectiveness of treatment of mild COPD, apart from smoking cessation, is lacking [28, 36]. Erroneous interventions also constitute an unnecessary financial burden for society.

We applaud the GOLD committee for raising interest in COPD research. However, over-diagnosis will lead to the inclusion of subjects who do not have COPD into the research pool, thereby adding noise to any signals that researchers are looking for when trying to unravel the causes of COPD and hence find potential treatments. Also problematic is excluding younger subjects who may have airway obstruction (false negatives) when the fixed ratio is used [4, 5, 10, 16, 18, 21, 37-40]. For research purposes, it is far better to limit recruitment to subjects who definitely have the disease, but this urgently requires adjustment of the present guideline on a fixed FEV1/FVC ratio.

We appreciate the consequences of changing course when so many societies and organisations will be affected by replacing the fixed ratio by the lower limit of normal, and more importantly general practitioners and clinicians may have to review and revise previous diagnoses. However, in the light of new evidence it is never too late to change a decision made in good faith. We are therefore appealing to you, members of the GOLD committees, to change the method by which mild airway obstruction is defined by the GOLD guidelines in order to abandon the fixed ratio forever in favour of the lower limit of normal.

P.H. Quanjer ${ }^{*, f f}$, P.L. Enright ${ }^{\#, f f}$, M.R. Miller ${ }^{\boldsymbol{\varphi}, f f}$, J. Stocks ${ }^{+, f f}$, G. Ruppel ${ }^{\S, f f}$, M.P. Swanney ${ }^{f, f f}$, R.O. Crapo ${ }^{* *, f f}$,

O.F. Pedersen ${ }^{\# \#, f f}$, E. Falaschetti ${ }^{\text {थศ }, f f}$, J.P. Schouten ${ }^{++, f f}$ and

R.L. Jensen ${ }^{\S \S, f f}$

*Dept of Pulmonary Diseases and Dept of Paediatrics, Erasmus Medical Centre, Erasmus University, Rotterdam, The Netherlands. "College of Public Health, The University of Arizona, Tucson, AZ, USA. "Dept of Medicine, University Hospital Birmingham NHS Trust, Birmingham, UK. ${ }^{+}$Portex Respiratory Unit, UCL, Institute of Child Health. ${ }^{\S}$ Pulmonary Function Laboratory, Saint Louis University Hospital, St. Louis MO, USA. ${ }^{f}$ Respiratory Physiology Laboratory, Christchurch Hospital, Canterbury District Health Board, Christchurch, New Zealand. **Pulmonary Division, LDS Hospital and University of Utah, Salt Lake City, UT, USA. \#\#Institute of Public Health, Dept of Environmental and Occupational 
Medicine, University of Aarhus, Aarhus, Denmark. " Epidemiology and Public Health, University College London, London, UK. ${ }^{++}$Dept of Epidemiology, University Medical Center Groningen, University of Groningen, Groningen, The Netherlands. ${ }^{\S \S}$ Pulmonary Division, LDS Hospital and University of Utah, Salt Lake City, UT, USA. ${ }^{f f}$ All authors are members of, and represent, The Pulmonaria Group.

Statement of Interest: Statements of interest for M.R. Miller and P.L. Enright can be found at www.erj.ersjournals.com/ site/misc/statements.xhtml

\section{Acknowledgements:}

Organisations endorsing this open letter: ANZSRS: Australian and New Zealand Society of Respiratory Science. ARTP: Association for Respiratory Technology and Physiology. CAHAG: COPD \& Astma Huisartsen Advies Groep (COPD \& Asthma GP Advisory Group). SKL: Dutch Paediatric Repiratory Society. Education for Health, Warwick, UK. National Respiratory Training Center, Suffolk, VA, USA. NHG: Nederlands Huisartsen Genootschap (Dutch Society of GPs). NVALT: Dutch Thoracic Society. NVLA: Nederlandse Vereniging Longfunctie Analisten (Dutch Society of Respiratory Technicians). French Physiological Society. PCRS - UK: Primary Care Respiratory Society United Kingdom. SPLF: Société Scientifique de Médecine Générale. SSMG: Société Scientifique de Médecine Générale. WONCA: World Organization of Family Doctors.

Individuals endorsing this open letter: S. Aaron, Ottawa, Canada P. Adab, Birmingham, UK. S.K. Agarwal, Raleigh-Durham, NC, USA. A.N. Aggarwal, Chandigarh, India. O.A. Al-Rawas, Muscat, Oman. S.C. Arce, Buenos Aires, Argentina. B.G.M. Arets, Utrecht, the Netherlands. B. Bake, Göteborg, Sweden. L. Beckert, Christchurch, New Zealand. H.B. Saad, Sousse, Tunisia. N. Berend, Sydney, Australia. J.W. van den Berg, Zwolle, the Netherlands. E. Berglund, Gothenburg, Sweden. F. Blasi, Milan, Italy. P.W. Boros, Warsaw, Poland. O. Brändli, Wald, Switzerland. P-O. Bridevaux, Geneva, Switzerland. P.J. Briffa, Camperdown, Australia. B. Brockway, Dunedin, New Zealand. M. Brown, Brisbane, Australia. M. Bucknall, London, UK. J. Buffels, Leuven, Belgium. F.B. Rincón, Barcelona, Spain. D. Burton, Rockhampton, Australia. J. Canterbury, Denver, CO, USA R. Casaburi, Torrance, CA, USA. M. Cazzola, Rome, Italy. S. Centanni, Milan, Italy. I. Cerveri, Pavia, Italy. J. Concato, New Haven, CT, USA. B.G. Cooper, Birmingham, UK. A.S. Copur, North Chicago, IL, USA. A.G. Corsico, Pavia, Italy. J. Cotes, Durham, UK. D. Cramer, London, UK. A.J. Crockett, Adelaide, Australia. B.H. Culver, Seattle, WA, USA. R.E. Dales, Ottawa, ON, Canada. W. Dejsomritrutai, Bangkok, Thailand. P.N. Richard Dekhuijzen, Nijmegen, the Netherlands. E. Del Colle, Box Hill, Australia. H. Dunroy, Dunedin, New Zealand. D. Figurski, Canberra, Australia. M.J. Fletcher, Warwick, UK. C.A. Vaz Fragoso, New Haven, CT, USA. A. Fulambarker, Chicago IL, USA. K. Gain, Perth, Australia. M. Gappa, Wesel, Germany. M.W. Gerbase, Geneva, Switzerland. J. Gibson, Newcastle upon Tyne, UK. T.M. Gill, New Haven, CT, USA. K. Gooey, Victoria, Australia. C.J. Gore, Canberra, Australia. G. Hall, Perth, Australia. J.E. Hansen, Torrance, CA, USA. J.A. Hardie, Bergen, Norway. J. Henderson, Bristol, UK. E. Hnizdo, Morgantown, WV, USA. G. Hollaert, Dottignies, Belgium. S. Holmes, Shepton Mallet, UK. F. Hoppin, Pawtucket, RI, USA. B. Houltz, Gothenburg, Sweden. A. Houtkooper, Den Helder, the Netherlands. M. Hughes, London, UK. G. Hülskamp, Münster, Germany. M. Hurwitz, Canberra, Australia. R. Hyatt, Rochester, MN, USA. C.G. Irvin, Burlington, VT, USA. D.P. Johns, Hobart, Australia. R.E. Kanner, Salt Lake City, UT, USA. H. Khaled, Ksar Hellal, Tunisia. J. Kirkby, London, UK. J. Kivastik, Tartu, Estonia. D. Köhler, Kloster Grafschaft, Germany. N. Künzli, Basel, Switzerland. S.M. Lam, Hong Kong, China. A. Langhammer, Levanger, Norway. L.T. Tuyet Lan,
Ho Chi Min City, Vietnam. A.C.W. Lau, Hong Kong, China. M.L. Levy, Kenton, UK. C. Lisboa, Santiago, Chile. S. Lum, London, UK. N. MacIntyre, Durham, NC, USA. P.T. Macklem, Montreal, Canada. Y. Martinet, Nancy, France. G. McAvay, New Haven, CT, USA. J. McLachlan, Hamilton, New Zealand. A. Medbø, Tromsø, Norway. R.B. Mellins, New York, NY, USA. P.J.F.M. Merkus, Nijmegen, the Netherlands. A. Miller, New York, NY, USA. C. Mottram, Rochester, MN, USA. P. Myrianthefs, Kifissia, Greece. J. Olofson, Gothenburg, Sweden. S. Ostrowski, Lublin, Poland. S. Pakhalé, Ottawa, ON Canada. R. Pellegrino, Cuneo, Italy. C.A.C. Pereira, São Paulo, Brazil. E.L. Petsonk, MD, Morgantown, WV, USA. F. Pistelli, Pisa, Italy. K.V.V. Prasad, Hyderabad, India. J. Pray, Minneapolis, MN, USA. J.J. Pretto, Newcastle, Australia. C. Que, Beijing, China. S. Raju, Hyderabad, India. R.G. Roberts, Madison, WI, USA. N. Rothe, Paris, France. L. Rodwell, Brisbane, Australia. D. Robiony-Rogers, Wellington, Australia. M. Rosenfeld, Seattle, WA, USA. B. Rottier, Groningen, the Netherlands. S. Rouatbi, Sousse, Tunisia. R.E.K. Russell, London, UK. M. Rutten-van Mölken, Maastricht, the Netherlands. P.D. Scanlon, Rochester, MN, USA. O. van Schayck, Maastricht, the Netherlands. T. Schermer, Nijmegen, the Netherlands. P. Serrier, Paris, France. T. Similowski, Paris, France. I.R. Small, Aberdeen, UK. H. Stam, Rotterdam, the Netherlands. S. Stanojevic, London, UK. I. Steenbruggen, Zwolle, the Netherlands. P.S. Stephenson, Haverhill, Suffolk, UK. C. Straus, Paris, France. J. Sullivan, New York, NY, USA. M. Sunitha, Hyderabad, India. A. De Sutter, Ghent, Belgium. G.W. Sybrecht, Homburg/Saar, Germany. R.Taylor, Dunedin, New Zealand. F. Thien, Melbourne, Australia. B.R. Thompson, Melbourne, Australia. W. Tomalak, Rabka, Poland. D. Valeyre, Bobigny, France. P.H. Van Ness, New Haven, CT, USA. C. van Weel, Nijmegen, the Netherlands. J. Vandevoorde, Brussels, Belgium. D. Vilozni, Tel Aviv, Israel. W.M. Vollmer, Portland, OR, USA. K. Wasserman, Torrance, CA, USA. S.N. West, Sydney Australia. P. White, London, UK. L. Wilson, Invercargill, New Zealand. C. Wong, Dunedin, New Zealand. E.F.M. Wouters, Maastricht, the Netherlands. J. Zieliński, Warsaw, Poland.

\section{REFERENCES}

1 Quanjer PH, Tammeling GJ, Cotes JE, et al. Lung volumes and forced ventilatory flow. Eur Respir J 1993; 6: Suppl. 16, 5-40.

2 Falaschetti E, Laiho Primatesta P, et al. Prediction equations for normal and low lung function from the Health Survey for England. Eur Respir J 2004; 23: 456-463.

3 Stanojevic S, Wade A, Stocks J, et al. Reference ranges for spirometry across all ages. A new approach. Am J Respir Crit Care Med 2008; 177: 253-260.

4 www.spirxpert.com/GOLD.html, downloading the software gives access to over 80 sets of prediction equations and over 50,000 data demonstrating how the GOLD criteria lead to under diagnosis in young subjects and over diagnosis in those over $50 \mathrm{yrs}$.

5 www.spirxpert.com/controversies/controversy.html explains why the use of a fixed ratio is flawed.

6 Stanojevic S, Wade A, Stocks J. Reference values for lung function: past, present and future. Eur Respir J 2010; 36: 12-19.

7 Hardie JA, Buist AS, Vollmer WM, et al. Risk of over-diagnosis of COPD in asymptomatic elderly never-smokers. Eur Respir J 2002; 20: $1117-1120$.

8 Celli BR, Halbert RJ, Isonaka S, et al. Population impact of different definitions of airway obstruction. Eur Respir J 2003; 22: 268-273.

9 Roberts SD, Farber MO, Knox KS, et al. FEV1/FVC ratio of $70 \%$ misclassifies patients with obstruction at the extremes of age. Chest 2006; 130: 200-206.

10 Aggarwal AN, Gupta D, Behera D, et al. Comparison of fixed percentage method and lower confidence limits for defining limits of normality for interpretation of spirometry. Respir Care 2006; 51: 737-743. 
11 Miller MR, Steenbruggen I, Quanjer PH, et al. Defining the lower limit of normal for FEV1/ FVC. Am J Respir Crit Care Med 2007; 176: 101-102.

12 Miller MR. What defines abnormal lung function? Thorax 2007; 62: 1107.

13 Petsonk EL, Hnizdo E, Attfield M. Definition of COPD GOLD stage I. Thorax 2007; 62: 1107-1108.

14 Medbø A, Melbye H. Lung function testing in the elderly - Can we still use the FEV1/FVC $<70 \%$ as a criterion for COPD? Respir Med 2007; 101: 1097-1105.

15 Shirtcliffe $\mathrm{P}$, Weatherall M, Marsh S, et al. COPD prevalence in a random population survey: a matter of definition. Eur Respir J 2007; 30: 232-239.

16 Vollmer WM, Gíslason B, Burney $\mathrm{P}$, et al. Comparison of spirometry criteria for the diagnosis of COPD: results from the BOLD study. Eur Respir J 2009; 34: 588-597.

17 Miller MR, Pedersen OF, Pellegrino R, et al. Debating the definition of airflow obstruction: time to move on? Eur Respir J 2009; 34: 527-528.

18 Swanney MP, Ruppel G, Enright PL, et al. Using the lower limit of normal for the $\mathrm{FEV}_{1} / \mathrm{FVC}$ ratio reduces the misclassification of airway obstruction. Thorax 2008; 63: 1046-1051.

19 Olofson J, Bake B, Tengelin MN, et al. COPD 'diagnosis' based on spirometric reference equations. Clin Respir J 2008; 2: 214-219.

20 Ko FWS, Woo J, Tam W, et al. Prevalence and risk factors of airflow obstruction in an elderly Chinese population. Eur Respir J 2008; 32: 1472-1478.

21 Lau AC, Ip MS, Lai CK, et al. Variability of the prevalence of undiagnosed airflow obstruction in smokers using different diagnostic criteria. Chest 2008; 133: 42-48.

22 Schermer TR, Smeele IJ, Thoonen BP, et al. Current clinical guideline definitions for airflow obstruction leads to substantial overdiagnosis of COPD in primary care. Eur Respir J 2008; 32: 945-952.

23 Levy ML, Quanjer PH, Booker R, et al. Diagnostic spirometry in primary care: proposed standards for general practice compliant with American Thoracic Society and European Respiratory Society recommendations. Prim Care Respir J 2009; 18: 130-147.

24 Schermer TRJ, Quanjer PH. COPD screening in primary care: who is sick? Prim Care Respir J 2007; 16: 49-53.

25 Pérez-Padilla R, Hallal PC, Vázquez-García JC, et al. Impact of bronchodilator use on the prevalence of COPD in populationbased samples. COPD 2007; 4: 113-120.

26 Vaz Fragoso CA, Concato J, McAvay G, et al. The ratio of forced expiratory volume in 1-second to forced vital capacity as a basis for establishing chronic obstructive pulmonary disease. Am J Respir Crit Care Med 2010; 181: 446-451.

27 Miller MR, Quanjer PH, Swanney MP, et al. Interpreting lung function data using $80 \%$ predicted and fixed thresholds misclassifies more than $20 \%$ of patients. Chest 2011; 139: 52-59.

28 Enright PL. GOLD stage I is not a COPD risk factor. Thorax 2007; 62: 1107

29 Miller MR, Pincock AC. Predicted values: how should we use them? Thorax 1988; 43: 265-267.

30 ATS Statement. Lung function testing: selection of reference values and interpretative strategies. Am Rev Respir Dis 1991; 144: 1202-1218.

31 Pellegrino R, Viegi G, Brusasco V, et al. Interpretative strategies for lung function tests. Eur Respir J 2005; 26: 948-968.

32 Townsend MC. Conflicting definitions of airways obstruction: drawing the line between normal and abnormal. Chest 2007; 131 335-336.

33 Kerstjens HAM. The GOLD classification has not advanced understanding of COPD. Am J Respir Crit Care Med 2004; 170: 212-213.

34 Enright P, Quanjer P. Don't diagnose mild COPD without confirming airway obstruction after an inhaled bronchodilator. COPD 2007; 4: 89-90.

35 Culver BH. Interpretation of spirometry: we can do better than the GOLD standard. Editorial. Respir Care 2006; 51: 719-721.

36 Wilt T, Niewoehner DE, Kim C-B, et al. Use of spirometry for case finding, diagnosis, and management of chronic obstructive pulmonary disease (COPD). Evidence report/technology assessment no. 121. (Prepared by the Minnesota Evidence-based Practice Center under contract no. 290-02-0009.) AHRQ Publication No. 05-E017-2. Rockville, Agency for Healthcare Research and Quality, 2005.

37 Hnizdo E, Glindmeyer HW, Petsonk EL, et al. Case definitions for chronic obstructive pulmonary disease. COPD 2006; 3: 1-6.

38 Hansen JE, Sun X-G, Wasserman K. Spirometric criteria for airway obstruction. Use percentage of FEV1/FVC ratio below the fifth percentile, not $<70 \%$. Chest 2007; 131: 349-355.

39 Cerveri I, Corsico AG, Accordini S, et al. Underestimation of airflow obstruction among young adults using FEV1/FVC $<70 \%$ as a fixed cut-off: a longitudinal evaluation of clinical and functional outcomes. Thorax 2008; 63: 1040-1045.

40 Cerveri I, Corsico AG, Accordini S, et al. What defines airflow obstruction in asthma? Eur Respir J 2009; 34: 568-573.

DOI: $10.1183 / 09031936.00135110$ 